UDC 614.71:612.017.1-053.6

DOI: $10.21668 /$ health.risk/2021.2.12.eng

Research article

\title{
RISK OF SENSITIZATION TO ECOPOLLUTANTS IN TEENAGERS WITH INHERITED CHEMICAL BURDEN
}

\section{L.B. Masnavieva, N.V. Efimova, I.V. Kudaeva}

East-Siberian Institute of Medical and Ecological Research, 12a the 3rd micro-district, Angarsk, 665827, Russian Federation

At present allergic diseases are detected in $30 \%$ people and their frequency is only growing. A significant role in allergic pathology occurrence belongs to ambient air contamination and chemicals being introduced not only into children's bodies, but their parents' ones as well since pollutants can act as allergens and sensitizing agents.

Our research goal was to examine influence exerted by parents' pre-gestation exposure to chemicals on sensitization among teenagers living in an area where ambient air was contaminated.

We examined overall immunoglobulin E contents and leukocytes migration inhibition test with formaldehyde and sodium nitrite in 115 teenagers whose parents worked under adverse working conditions at chemical and petrochemical enterprises and in 244 schoolchildren whose parents didn't have any occupational contacts with chemicals. Each group was divided into sub-groups depending on inhalation chemical burden on schoolchildren's bodies caused by ambient air contamination and contaminated air indoors (with hazard index (HI) for immune disorders being lower than 2 and $H I \geq 2$ ).

The research allowed establishing that teenagers whose parents had worked at chemical and petrochemical enterprises during a pre-gestation period had elevated IgE contents more frequently as well as changes in leukocytes migration inhibition test with formaldehyde; it indicated there was sensitization to this chemical. Parents' occupational contacts with chemicals led to an increase in relative risks of elevated igE contents and 2.5 times higher sensitization among schoolchildren with $\mathrm{HI}<2$. Risk that sensitization to formaldehyde might occur was equal to 2.3 among senior schoolchildren with $H I \geq 2$ whose parents worked at chemical enterprises.

Key words: pre-gestation chemical exposure, teenagers, parents, sensitization, immunoglobulin E, leukocytes migration inhibition test, ambient air contamination.

Over the last decades a number of allergic pathology cases has been growing actively all over the world and now this pathology is diagnosed in each third person. It deteriorates life quality and becomes a heavy burden for a society $[1,2]$. Ambient air contamination makes a significant contribution into a risk of health disorders among population and ecopollutants can act as allergens and sensitizing agents and cause allergic diseases [3, 4]. It has been proven that ambient air contamination with formaldehyde, benzpyrene, phenol, and nitrogen dioxide produces effects on immune sys- tem functioning via inducing synthesis of antiinflammatory cytokines, reducing IgA contents, increasing contents of specific autoantibodies, inhibiting cell death via apoptosis and activating it via necrosis. It is also associated with allergic pathology among adults and children [5-8].

Sanitary-hygienic assessment of working area air at chemical productions revealed certain chemicals including butanol, dimethylamine, cobalt tetracarbonyle hydride, methyl tributyl ether, carbon oxide, and saturated hydrocarbons [9]. Chemicals in work-

(C) Masnavieva L.B., Efimova N.V., Kudaeva I.V., 2021

Lyudmila B. Masnavieva - Doctor of Biological Sciences, Senior Researcher at the laboratory for immunological, biochemical, molecular and genetic research in hygiene (e-mail: Masnavieva_Luda@mail.ru; tel.: +7 (964) 657-11-62; ORCID: http://orcid.org/0000-0002-1400-6345).

Natalia V. Efimova - Doctor of Medical Sciences, Professor, Leading Researcher at the Laboratory for Ecological and Hygienic Research (e-mail: medecolab@inbox.ru; tel.: +7 (3955) 58-69-10; ORCID: http://orcid.org/0000-0001-7218-2147).

Irina V. Kudaeva - Associate Professor, Deputy Director for Research, Head of the clinical and diagnostic laboratory (e-mail: Kudaeva_Irina@mail.ru; tel.: +7 (3955) 58-69-30; ORCID: http://orcid.org/0000-0002-5608-0818). 
ing area air, even when they occur in concentrations not exceeding hygienic standards, can exert negative impacts on reproductive health of workers employed at chemical productions [10].

There are a lot of data in literature on influence exerted by alcohol, smoking, and other negative factors on future generation's health during pregnancy [11-15]. In recent years some data have been published on transgenerational epigenetic inheritance and its role in adaptation and occurrence of diseases in children [16-18]. It was revealed that chemotherapy applied in treating fathers for cancer modified sperm epigenome and entailed probable transgenerational transfer [19]. It was also established that when male and female rats were poisoned with combustion products prior to coupling, it led to changes in offspring's behavior and development [20]; when parents, either mothers or fathers or both, worked under adverse conditions, it was associated with an increase in primary morbidity, chronic pathology of the upper respiratory tracts, and frequent positive tests for allergens in children [21]. It was also shown that threats of miscarriage, gestosis in the first half of pregnancy, intrauterine hypoxia, and delayed fetus development in women employed at petroleum processing enterprises were to a great extent occupationally induced [10,21].

Our research goal was to examine influence exerted by parents' pre-gestation exposure to chemicals on sensitization among teenagers living in an area where ambient air was contaminated.

Data and methods. Our research was performed in two industrial cities located in Irkutsk region with big chemical and petrochemical enterprises operating there. Schoolchildren were examined in spring prior to blooming season; prior to any examination parents (legal representatives) were questioned and then gave their written informed consent to let teenagers take part in the research. We took the following criteria for including children into the research: they per- manently lived and attended schools on the examined territory; they were 14-17 years old; they didn't have any signs of an acute respiratory disease at the moment of the research.

To assess influence exerted by parents' exposure to chemicals in pre-gestation period, we took data on occupational conditions at workplaces and pollutants contents in working area air. Data on chemicals contents in working area air were taken from databases belonging to Rospotrebnadzor Regional Office in Irkutsk region, Rosgidromet, and also from research works performed by the East Siberian Institute for Medical and Ecologic Research [5, 9, 22, 23]. Longitude research performed by N.M. Meshchakova et al. [22] revealed that in 1988-1994 concentrations of certain chemicals in working area air at vinyl chloride production were substantially higher than maximum permissible concentrations. Thus, vinyl chloride contents amounted to $21.1-217 \mathrm{mg} / \mathrm{m}^{3}$ and dichloroethane contents amounted to $140.7-156.0 \mathrm{mg} / \mathrm{m}^{3}$; then production equipment was modernized (1995-2000) and single concentrations of these chemicals didn't exceed 1.8 maximum permissible concentration (MPC) after that [22]. Over a period starting from 2001 concentrations of dimethylamine, methanol, butanol, and carbon oxide varied from 0.20 to $0.55 \mathrm{mg} / \mathrm{m}^{3}, 1.0-11.0 \mathrm{mg} / \mathrm{m}^{3}, 1.0-4.0 \mathrm{mg} / \mathrm{m}^{3}$, $4.4-10.0 \mathrm{mg} / \mathrm{m}^{3}$ accordingly and didn't exceed MPC at enterprises that produced methanol, methylamines and butanol via oxo-synthesis and methyl-tributyl ether [9]. Ambient air contamination was estimated as high in the examined cities in 1990-1995. Hazard index (HI) for health disorders among population, taken without benzpyrene, varied from 8 to 10.2; priority pollutants included nitrogen dioxide, hydrogen sulfate, and formaldehyde. In 2015-2017 HI reached 15.9 [23].

When assessing chemical inhalation exposure on teenagers' bodies we took into account ambient air quality and pollutants contents in indoor air since the questionnaire revealed that teenagers spent most their time 
at home or at school (20-23 hours a day). To calculate personified $\mathrm{HI}$ of immune disorders among teenagers, we took data on contents of immune-tropic pollutants in ambient air, in air inside homes and classrooms, as well as schoolchildren's anthropometric and spirometric data and data on their daily routines [24]. The greatest contribution into individual $\mathrm{HI}$ of immune disorders was made by formaldehyde; its maximum concentrations reached $0.005 \mathrm{mg} / \mathrm{m}^{3}$ inside classrooms; homes, 0.006 $\mathrm{mg} / \mathrm{m}^{3}$; ambient air, $0.006 \mathrm{mg} / \mathrm{m}^{3}$ (reference concentrations is $0.003 \mathrm{mg} / \mathrm{m}^{3}$ ) [5].

We spotted teenagers among the examined school children whose parents hadn't contacted chemicals in their occupational activity; they were included into the group I (244 schoolchildren). Teenagers whose parents had worked under adverse conditions at chemical and petrochemical enterprises were included into the group II (115 schoolchildren). Shares of smoking teenagers and those exposed to passive smoking were comparable in Groups I and II (62.4 and $60.0 \%$ accordingly). $H I$ values for immune disorders among schoolchildren varied from 1.34 to 2.7 and allowed us to divide both groups into subgroups $a$ and $b$. Subgroups $\mathrm{I}_{\mathrm{a}}$ and $\mathrm{II}_{\mathrm{a}}$ were made up of teenagers with $\mathrm{HI}<2$ (114 and 56 people accordingly); subgroups $\mathrm{I}_{\mathrm{b}}$ and $\mathrm{II}_{\mathrm{b}}$, teenagers with $H I \geq 2$ (130 and 59 people accordingly) (Figure).

Allergic proneness and sensitization of schoolchildren's bodies to chemicals were estimated as per total immunoglobulin $\mathrm{E}(\mathrm{IgE})$ and migration index (MI) in leukocytes migration inhibition (LMI) with formaldehyde and sodium nitrite. IgE was determined in blood serum via solid phase ELISA test with Total IgE reagents kit ("Xema", Germany). Contents equal to $1.3-70.0 \mathrm{IU} / \mathrm{ml}$ were taken as referent ones. Leukocytes extracted from whole blood were used in LMI. Formaldehyde or sodium nitrite was used as a chemokinetic factor in the reaction; mitogen phytohaemagglutinin was taken as positive control; cultural medium without chemo-attractant was taken as intact control [5]. MI varying from 0.80 to 1.20 was considered referent.

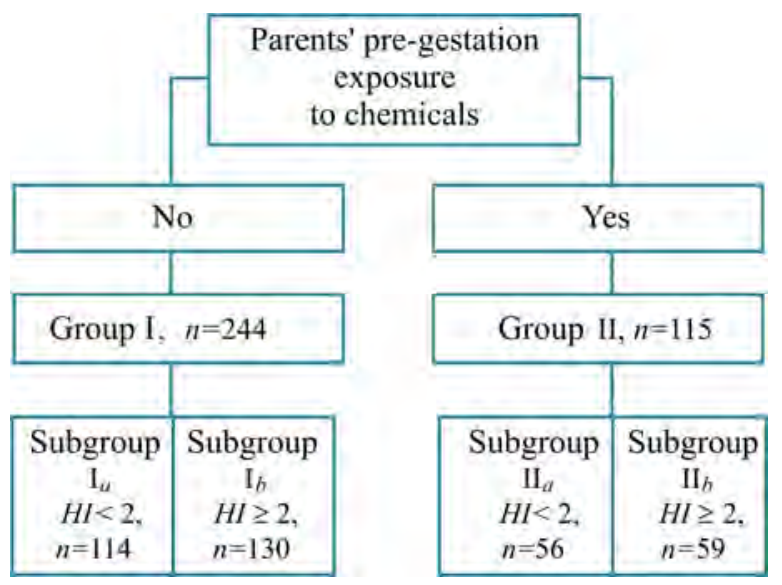

Figure. Research design

To compare quantitative parameters between groups, we took Mann - Whitney U-test (results are given as median $(\mathrm{Me})$ and 25-75 quartiles (LQ-UQ)); and chi-square $\left(\chi^{2}\right)$ with Yates correction. Frequency of a parameter occurrence in the sampling was calculated as per 100 examined people and given with $95 \%$ confidence interval $(C I)$. Relative risk was assessed as per odds ratio $(O R)$ with $95 \% C I$. Critical statistical significance of differences (p) was taken at 0.05 . All the results were statistically processed with Statistica 6.0 applied software.

Results and discussion. Having compared average IgE contents in different groups, we revealed that it tended to grow in Group II. Analysis of migration indexes of LMI with formaldehyde and sodium nitrite $\left(\mathrm{MI}_{\mathrm{f}}\right.$ and $\mathrm{MI}_{\mathrm{s}}$ accordingly) didn't reveal any significant differences depending on parents' occupational contacts with chemicals prior to a child birth, both in groups taken as whole and in subgroups with different $H I$ (Table 1).

We assessed how frequently the examined parameters deviated from reference levels; the assessment revealed that elevated $\mathrm{IgE}$ levels were more frequent among teenagers with inherited chemical burden than among their counterparts whose parents hadn't contacted chemicals at their workplaces (Table 2). These differences were also significant when frequency of elevated IgE levels was compared in subgroups made up of schoolchildren exposed to different inhalation burden. 
Table 1

Allergic proneness revealed among teenagers with inherited chemical burden who lived on a territory where ambient air was contaminated, Me (LQ-UQ)

\begin{tabular}{|c|c|c|c|c|}
\hline Parameter & Subgroups & Group I & Group II & $p$ \\
\hline \multirow{3}{*}{ IgE, } & all & $26.17(4.11-66.03)$ & $36.21(7.37-93.58)$ & 0.065 \\
\cline { 2 - 5 } & $H I<2$ & $24.11(8.33-53.76)$ & $33.76(11.40-105.01)$ & 0.610 \\
\cline { 2 - 5 } & $H I \geq 2$ & $27.04(2.08-83.73)$ & $36.78(3.04-93.58)$ & 0.489 \\
\hline \multirow{3}{*}{$\mathrm{MI}_{\mathrm{f}}$} & all & $0.97(0.84-1.06)$ & $0.92(0.82-1.11)$ & 0.508 \\
\cline { 2 - 5 } & $H I<2$ & $0.96(0.76-1.10)$ & $0.89(0.54-0.96)$ & 0.276 \\
\cline { 2 - 5 } & $H I \geq 2$ & $0.98(0.85-1.05)$ & $1.00(0.82-1.13)$ & 0.918 \\
\hline \multirow{3}{*}{$\mathrm{MI}_{\mathrm{s}}$} & all & $0.97(0.85-1.09)$ & $0.93(0.71-1.21)$ & 0.661 \\
\cline { 2 - 5 } & $H I<2$ & $0.92(0.74-0.98)$ & $0.77(0.58-0.97)$ & 0.227 \\
\cline { 2 - 5 } & $H I \geq 2$ & $1.00(0.86-1.14)$ & $0.96(0.82-1.29)$ & 0.736 \\
\hline
\end{tabular}

N o t e : $p$ is statistical significance of differences between Groups I and II;

$\mathrm{MI}_{\mathrm{f}}, \mathrm{MI}_{\mathrm{s}}$ are migration indexes for leukocytes in leukocytes migration inhibition with formaldehyde and sodium nitrite accordingly.

Table 2

Frequency of allergic proneness parameters deviating from reference levels in teenagers with inherited chemical burden and exposed to ambient air contamination

\begin{tabular}{|c|c|c|c|c|}
\hline \multirow{2}{*}{ Parameter } & \multirow{2}{*}{ Subgroups } & \multicolumn{2}{|c|}{ Deviation frequency, per 100 examined [CI] } & \multirow{2}{*}{$p$} \\
\cline { 2 - 5 } & & Group I & Group II & \\
\hline \multirow{3}{*}{$\begin{array}{c}\text { IgE, } \\
\text { IU/ml }\end{array}$} & all & $22.22[16.79-27.65]$ & $39.13[30.21-48.05]$ & 0.001 \\
\cline { 2 - 5 } & $H I<2$ & $17.12[10.11-24.12]$ & $33.96[25.27-42.66]$ & 0.015 \\
\cline { 2 - 5 } & $H I \geq 2$ & $27.19[15.21-39.17]$ & $43.55[31.21-55.89]$ & 0.022 \\
\hline \multirow{3}{*}{ MI $_{\mathrm{f}}$} & all & $34.97[27.15-42.78]$ & $56.36[43.26-69.47]$ & 0.007 \\
\cline { 2 - 5 } & $H I<2$ & $37.14[21.13-53.15]$ & $62.50[38.78-86.22]$ & 0.083 \\
\cline { 2 - 5 } & $H I \geq 2$ & $34.26[25.31-43.21]$ & $53.85[38.20-69.49]$ & 0.028 \\
\hline \multirow{3}{*}{$\mathrm{MI}_{\mathrm{s}}$} & all & $34.58[25.57-43.59]$ & $32.00[19.07-44.93]$ & 0.712 \\
\cline { 2 - 5 } & $H I<2$ & $40.00[23.77-56.23]$ & $37.50[13.78-61.22]$ & 0.892 \\
\cline { 2 - 5 } & $H I \geq 2$ & $24.73[15.96-33.50]$ & $29.41[14.10-44.73]$ & 0.649 \\
\hline
\end{tabular}

N o t e : $p$ is statistical significance of differences between Groups I and II;

$C I$ is $95 \%$ confidence interval;

$\mathrm{MI}_{\mathrm{f}}, \mathrm{MI}_{\mathrm{s}}$ are migration indexes for leukocytes in leukocytes migration inhibition with formaldehyde and sodium nitrite accordingly.

We also revealed difference in frequency of sensitization to formaldehyde in LMI between Groups I and II. MI values deviating from reference levels were more frequent in case there was inherited chemical burden. As for teenagers with $H I<2$, we detected only a trend for a growth in a share of people with $\mathrm{MI}_{\mathrm{f}}$ value being beyond the reference range

(subgroup $\mathrm{II}_{\mathrm{a}}$ against subgroup $\mathrm{I}_{\mathrm{a}}$ ). Frequency of deviations in these parameters was statistically significantly higher among teenagers with $H I \geq 2$ and inherited chemical burden (subgroup $\mathrm{II}_{\mathrm{b}}$ ) than among their counterparts without it (subgroup $\mathrm{I}_{\mathrm{b}}$ ). We should note that MI deviations from the reference range could be both elevated and decreased inhibition 
(MI being lower than 0.8 or higher than 1.2 accordingly). There were 3.2-4 times more people with elevated inhibition with formaldehyde in both subgroups at $H I<2(28.57$ [13.60-43.54] \% and 50.00 [40.57-59.43] \% for subgroups $\mathrm{I}_{\mathrm{a}}$ and $\mathrm{II}_{\mathrm{a}}$ accordingly) than with decreased one (8.57 [0.00-17.85] \% and 12.50 [6.26-18.74]\%). As HI grew, a share of people with elevated leukocytes migration in a reaction with formaldehyde went down, both among schoolchildren without inherited chemical burden and with it (15.74 [0.00-33.59] \% and 23.08 [9.85-36.30] \% for subgroups $\mathrm{I}_{\mathrm{b}}$ and $\mathrm{II}_{\mathrm{b}}$ accordingly) and, on the contrary, a share of people with decreased migration grew $(18.52 \quad[0.00-37.55] \%$ and 30.77 [16.28-45.25] \% accordingly).

There were no differences in frequency of $\mathrm{MI}_{\mathrm{s}}$ deviations from reference values in subgroups with different $H I$ calculated for immune disorders among teenagers depending on their parents' contacts with chemicals. $\mathrm{MI}_{\mathrm{s}}$ deviations from the reference range were detected in each third teenager in groups with inherited chemical burden and among their counterparts without it and there were no differences in their frequency between the groups.

Elevated IgE levels and changed MI in a reaction with formaldehyde were more frequent among teenagers whose parents had contacted chemicals at their workplaces in pregestation period. It indicates that there is sensitization to formaldehyde as well as a higher risk that allergic diseases might occur. Relative risk of an increase in $\operatorname{IgE}$ contents among teenagers with inherited chemical burden was higher than 1 in the subgroup with $H I<2$ and was equal to 2.5 where as it was only 1.7 in the subgroup with $H I \geq 2$ and this increase was not statistically significant (Table 3 ).

Parents' occupational contacts with chemicals in pre-gestation period didn't exert any influence on a risk of sensitization to formaldehyde among teenagers with $H I<2$. But still, higher inhalation exposure to immune-tropic compounds together with inherited chemical burden caused elevated risk of sensitization to formaldehyde among teenagers. We didn't establish any influence exerted by parents' occupational contacts on a risk of sensitization to sodium nitrite.

Table 3

Relative risk of sensitization and allergic proneness among teenagers whose parents had contacted chemicals

\begin{tabular}{|c|c|c|c|c|}
\hline Parameter & Subgroups & OR $(C I)$ & $\chi^{2}$ & $p$ \\
\hline \multirow{4}{*}{$\mathrm{IgE}$} & all & $1.78(1.07-2.95)$ & 5.07 & 0.025 \\
\cline { 2 - 5 } & $H I<2$ & $2.49(1.17-5.29)$ & 5.83 & 0.016 \\
\cline { 2 - 5 } & $H I \geq 2$ & $1.37(0.69-2.72)$ & 0.79 & 0.375 \\
\hline \multirow{3}{*}{$\mathrm{MI}_{\mathrm{f}}$} & all & $2.43(1.28-4.58)$ & 7.72 & 0.006 \\
\cline { 2 - 5 } & $H I<2$ & $2.82(0.83-9.58)$ & 2.85 & 0.166 \\
\cline { 2 - 5 } & $H I \geq 2$ & $2.27(1.08-4.77)$ & 4.77 & 0.029 \\
\hline \multirow{2}{*}{$\mathrm{MI}_{\mathrm{s}}$} & all & $1.14(0.59-2.23)$ & 0.15 & 0.695 \\
\cline { 2 - 5 } & $H I<2$ & $0.90(0.27-3.04)$ & 0.03 & 0.866 \\
\hline
\end{tabular}

N o t e : $\chi^{2}$ are chi-square values; $p$ is statistical significance as per $\chi^{2}$ test;

$O R(C I)$ is odds ratio with $95 \%$ confidence interval;

$\mathrm{MI}_{\mathrm{f}}, \mathrm{MI}_{\mathrm{s}}$ are migration indexes for leukocytes in leukocytes migration inhibition with formaldehyde and sodium nitrite accordingly.

Our data indicate that contacts with chemicals by parents (fathers included) in a period before the examined children were born result in elevated risks of teenagers becoming allergic. It is in line with results obtained via research performed with participating workers employed at industrial rubber production as well as at hothouses where chemical compounds were used as fertilizers $[25,26]$. There are data in these works on a decrease in non-specific resistance and protective-adaptive capabilities of children's bodies as well as on an increase in morbidity including allergic diseases. Besides, S.H. Arshad et al. revealed that inhalation exposure of mothers or grandmothers to chemical compounds caused by smoking prior to pregnancy was associated with allergic diseases in children [27]. It is well-known that most allergic diseases have IgE-dependent development mechanism and are accompanied with an increase in contents of this im- 
munoglobulin in blood serum. It is diagnostically important to determine total $\operatorname{IgE}$ in case of allergic pathology since its contents correlate with concentrations of allergenspecific IgE in most cases [28, 29]. When there are only initial signs of sensitization to allergens and there are no apparent symptoms of an allergic disease, specific $\operatorname{IgE}$ can already start to occur [28]. Therefore, elevated IgE contents indicate there is sensitization, regardless of allergic pathology being apparent or not. Relative risk of this immunoglobulin occurring in a body in elevated contents that is higher than 1 indicates that parents' occupational contacts with chemicals play a significant role in sensitization developing in their children's bodies. We should note that relative risk of elevated $\mathrm{IgE}$ contents caused by parents' contacts with chemicals during pre-gestation period was higher among teenagers with $H I<2$ than among those with $H I \geq 2$. It is due to differences in growth in a share of people with elevated IgE contents depending on inhalation exposure to immune-tropic compounds among teenagers with inherited chemical burden and without it. Effects produced by contaminated ambient air were stronger among teenagers without inherited chemical burden. Thus, as HI grew, frequency of elevated $\mathrm{IgE}$ increased by 1.6 times in Group I (from 17 to $27 \%, p=0.126$ when subgroups $\mathrm{I}_{\mathrm{a}}$ and $\mathrm{I}_{\mathrm{b}}$ were compared); and by 1.3 times in Group II (from 34 to $43 \%, p=0.187$ when subgroups $\mathrm{II}_{\mathrm{a}}$ and $\mathrm{II}_{\mathrm{b}}$ were compared). We should note that both risk factors combined (parents' pre-gestation contact with chemicals and $\mathrm{HI}$ calculated for immune disorders being equal to 2 or higher) caused a significant increase in OR (2.54 (1.19-5.40), $\left.\chi^{2}=6.03, p=0.015\right)$.

It is well known, that both biologic allergens (animal dandruff and hair, housedust ticks, plant and mushroom pollen) and chemical contaminants (ozone, sulfur dioxide, nitrogen dioxide, diesel fuel combustion products, tobacco smoke, etc.) can act as sensitizing agents [30]. Therefore, a contri- bution into occurring sensitization to formaldehyde can be made both by inherited chemical burden and elevated ambient air contamination with immune-tropic chemicals. It was established that an increase in inhalation exposure for teenagers didn't result in growing OR of changing MI in LMI with formaldehyde in Groups I and II $(0.88$ (0.40-1.95) and 0.75 (0.24-2.4) accordingly) but a risk of sensitization to formaldehyde increased only under elevated inhalation exposure to immune-tropic chemicals $(H I \leq 2)$. This detected increase in a risk of sensitization to formaldehyde is in line with research results that revealed more frequent positive skin tests to household, epidermal and pollen allergens among teenagers living in cities with heavily contaminated ambient air whose parents contacted adverse chemicals at their workplaces [22]. Chemical pregestation exposure is an epigenetic factor and it can become apparent via changes in methylation of certain DNA section in genes associated with allergic diseases development. Thus, it was established that DNA methylation in promoter of the neuropeptide S-receptor 1 that was linked to asthma and allergy occurrence was associated not only with parents and their children suffering from allergy but also with environmental exposure [27]. These results indicate that epigenetic factors exert certain influence on occurring sensitization to formaldehyde among teenagers living under adverse exposure to ambient air being contaminated with immune-tropic chemicals.

Conclusion. Our research allowed establishing that teenagers whose parents had worked at chemical and petrochemical enterprises during pre-gestation period more frequently had elevated IgE contents in blood serum as well as changes in LMI with formaldehyde indicating there was sensitization to this chemical. Parents' occupational contacts with chemicals resulted in 2.5 times higher relative risk of elevated IgE contents, sensitization, and allergic pathology development among schoolchildren living under moderate exposure 
to ambient air being contaminated with immune-tropic chemicals $(H I<2)$. Risk of sensitization to formaldehyde amounted to 2.3 for teenagers living under inhalation exposure with $H I \geq 2$ and with parents who had worked at chemical enterprises. Therefore, inhalation exposure to immune-tropic chemicals and parents' occupational contacts with chemicals during pre-gestation period cause elevated risks of sensitization and allergic diseases among teenagers.

Funding. The study was financially supported within the State Task and by funds belonging to the Eastern Siberian Institute for Medical and Ecologic Research.

Conflict of interests. The authors declare there is no any conflict of interests.

\section{References}

1. Il'ina N.I., Luss L.V., Nazarova E.V. Environment and allergies. Meditsinskii opponent, 2019, vol. 6 , no. 2, pp. 12-17 (in Russian).

2. Simon D. Recent Advances in Clinical Allergy and Immunology. Int Arch Allergy Immunol, 2018, vol. 177, no. 4, pp. 324-333. DOI: 10.1159/000494931

3. Vyalkov A.I., Bobrovnitskii I.P., Rakhmanin Yu.A., Razumov A.N. Ways of improving the health organization in the conditions of growing ecological challenges of life safety and population health. Russian Journal of Rehabilitation Medicine, 2017, no. 1, pp. 24-41 (in Russian).

4. Trifonova T.A., Martsev A.A. Assessment of the impact of air pollution on population morbidity rate in the Vladimir region. Gigiena i sanitariya, 2015, vol. 94, no. 4, pp. 14-18 (in Russian).

5. Masnavieva L.B., Kudaeva I.V., Efimova N.V., Zhurba O.M. Individual exposure load of formaldehyde and adolescents' organism sensibilization. Ekologiya cheloveka, 2017, no. 6, pp. 3-8 (in Russian).

6. Hajat A., Allison M., Diez-Roux A.V., Jenny N.S., Jorgensen N.W., Szpiro A.A., Vedal S., Kaufman J.D. Long-term exposure to air pollution and markers of inflammation, coagulation, and endothelial activation: a repeat-measures analysis in the Multi-Ethnic Study of Atherosclerosis (MESA). Epidemiology, 2015, vol. 26, no. 3, pp. 310-320. DOI: 10.1097/EDE.000000000000026

7. Zhai L., Zhao J., Xu B., Deng Y., Xu Z. Influence of indoor formaldehyde pollution on respiratory system health in the urban area of Shenyang, China. Afr Health Sci, 2013, vol. 13, no. 1, pp. 137-143. DOI: $10.4314 /$ ahs.v13i1.1

8. Dolgikh O.V., Starkova K.G., Krivtsov A.V., Kazakova O.A., Mazunina A.A. Immunogenetic markers of the Siberia southern regions' population under the exposure of technogenous factors. Yakutskii meditsinskii zhurnal, 2019, vol. 66, no. 2, pp. 53-55 (in Russian).

9. Taranenko N.A., Meshchakova N.M., Shayakhmetov S.F. Assessment the sanitary-hygienic conditions of workplace air in chemical productions of petrochemical industry in eastern Siberia. Byulleten' Vostochno-Sibirskogo nauchnogo tsentra Sibirskogo otdeleniya Rossiiskoi akademii meditsinskikh nauk, 2014, vol. 97, no. 3, pp. 66-71 (in Russian).

10. Sivochalova O.V., Gainullina M.K., Yakupova A.Kh., Karimova L.K., Irmyakova A.R. Evaluation of the level of gynecological morbidity, etiological caused by the impact on workers of toxic substances. Meditsina truda i ekologiya cheloveka, 2015, no. 2, pp. 33-38 (in Russian).

11. Abaturov A.E. Influence of Exogenous Factors on Genomic Imprinting. 2. Effect of Bad Habits of Parents on Genomic Imprinting of the Descendants. Zdorov'e rebenka, 2016, vol. 74, no. 6, pp. 115-120. DOI: $10.22141 / 2224-0551.6 .74 .2016 .82143$

12. Pushkareva L.A., Vasil'eva E.A., Mikhailova I.V., Miroshnichenko I.V. Exposure to tobacco smoke offspring of rats Wistar. Rossiiskii immunologicheskii zhurnal, 2016, vol. 10 (19), no. 3, pp. 340-342 (in Russian).

13. Joubert B.R., Felix J.F., Yousefi P., Bakulski K.M., Just A.C., Breton C., Reese S.E., Markunas C.A. [et al.]. DNA Methylation in Newborns and Maternal Smoking in Pregnancy: Genome-wide Consortium Meta-analysis. Am. J. Hum. Genet., 2016, vol. 98, no. 4, pp. 680-696. DOI: 10.1016/j.ajhg.2016.02.019

14. Smejda K., Polanska K., Merecz-Kot D., Krol A., Hanke W., Jerzynska J., Stelmach W., Majak P., Stelmach I. Maternal Stress During Pregnancy and Allergic Diseases in Children During the First Year of Life. Respir. Care., 2018, vol. 63, no. 1, pp. 70-76. DOI: 10.4187/respcare. 05692 
15. Thacher J.D., Gruzieva O., Pershagen G., Neuman Å., van Hage M., Wickman M., Kull I., Melén E., Bergström A. Parental smoking and development of allergic sensitization from birth to adolescence. Allergy, 2016, vol. 71, no. 2, pp. 39-48. DOI: 10.1111/all.12792

16. Morgan H.L., Watkins A.J. Transgenerational Impact of Environmental Change. Adv. Exp. Med. Biol., 2019, no. 1200, pp. 71-89. DOI: 10.1007/978-3-030-23633-5_4

17. Lane M., Robker R.L., Robertson S.A. Parenting from before conception. Science, 2014, vol. 345 (6198), pp. 756-760. DOI: 10.1126/science.1254400

18. Shachar-Dadon A., Gueron-Sela N., Weintraub Z., Maayan-Metzger A., Leshem M. PreConception War Exposure and Mother and Child Adjustment 4 Years Later. J. Abnorm. Child. Psychol., 2017, vol. 45, no. 1, pp. 131-142. DOI: 10.1007/s10802-016-0153-9

19. Tremblay A., Beaud H., Delbès G. Transgenerational impact of chemotherapy: Would the father exposure impact the health of future progeny? Gynecol. Obstet. Fertil. Senol., 2017, vol. 45, no. 11, pp. 609-618. DOI: 10.1016/j.gofs.2017.09.004

20. Vokina V.A., Novikov M.A., Alekseenko A.N., Sosedova L.M., Kapustina E.A., Bogomolova E.S., Elfimova T.A. Experimental evaluation of effect of wildfire smoke exposure on reproductive function of small mammals and their offspring. Izvestiya Irkutskogo gosudarstvennogo universiteta. Seriya: Biologiya. Ekologiya, 2019, vol. 29, pp. 88-98 (in Russian).

21. Fesenko M.A., Sivochalova O.V., Fedorova E.V. Occupational reproductive system diseases in female workers employed at workplaces with harmful working conditions. Health Risk Analysis, 2017, no. 3, pp. 92-100. DOI: 10.21668/health.risk/2017.3.11.eng

22. Meshchakova N.M., Shayakhmetov S.F., Lemeshevskaya E.P., Zhurba O.M. Score exposition of chemical loads and their association with occupational risks in the modern manufacture of polyvinyl chloride. Gigiena i sanitariya, 2019, vol. 98, no. 10, pp. 1074-1078 (in Russian).

23. Efimova N.V., Abramatets E.A., Tikhonova I.V. The impact of the chemical factor on children's health with account of the early stages of ontogenesis. Gigiena i sanitariya, 2014, vol. 93, no. 6, pp. 83-86 (in Russian).

24. Masnavieva L.B., Kudaeva I.V., Efimova N.V. The levels of specific autoantibodies and risks for the formation of pathological processes in conditions of inhalation exposure to chemicals. Gigiena i sanitariya, 2015, vol. 94, no. 7, pp. 106-110 (in Russian).

25. Khakimova R.F., Dautov F.F., Yusupova N.Z. Study of allergic morbidity in children of female workers from various fields of national economy. Gigiena i sanitariya, 2007, no. 2, pp. 58-60 (in Russian).

26. Erdneeva N.V., Dautov F.F. Allergic disease of children of working women of rubber manufacture. Fundamental'nye issledovaniya, 2012, no. 4-1, pp. 163-166 (in Russian).

27. Arshad S.H., Karmaus W., Zhang H., Holloway J.W. Multigenerational cohorts in patients with asthma and allergy. J. Allergy. Clin. Immunol., 2017, vol. 139, no. 2, pp. 415-421. DOI: 10.1016/j.jaci.2016.12.002

28. Fedoseev G.B., Trofimov V.I., Timchik V.G., Negrutsa K.V., Golubeva V.I., Gorovneva E.V., Razumovskaya T.S., Birulya I.V. [et al.]. Infectious and noninfectious sensibilization of patients with bronchial asthma and chronic obstructive pulmonary disease. Rossiiskii allergologicheskii zhurnal, 2015, no. 6, pp. 39-53 (in Russian).

29. Novikova T.P., Dotsenko E.A. Diagnostic value of determination of total IGE in respiratory allergy. Laboratornaya diagnostika. Vostochnaya Evropa, 2019, vol. 8, no. 1, pp. 40-50 (in Russian).

30. Trukhan D.I., Natal'ya V.B., Valentina A.A. Actual aspects of diagnosis and treatment of atopic bronchial asthma. Terapiya, 2017, vol. 18, no. 8, pp. 53-62 (in Russian).

Masnavieva L.B., Efimova N.V., Kudaeva I.V. Risk of sensitization to ecopollutants in teenagers with inherited chemical burden. Health Risk Analysis, 2021, no. 2, pp. 123-130. DOI: 10.21668/health.risk/2021.2.12.eng

Received: 02.03.2021

Accepted: 04.06.2021

Published: 30.09 .2021 